\title{
Awareness of retinal screening in patients with Type 2 diabetes mellitus: Are we meeting standards of care?
}

\author{
Munazir Adil', Samreen Siddiqui ${ }^{2}$, Swati Waghdhare ${ }^{3}$, Amit Bhargava ${ }^{4}$, Sujeet $\mathrm{Jha}^{5}$ \\ ${ }^{1}$ Research Student, ${ }^{2}$ Research Associate, ${ }^{3,4}$ Consultant, ${ }^{5}$ Director, Institute of Endocrinology, Diabetes \& Metabolism,
} Max Healthcare Institute Ltd, New Delhi, India

Background: Since diabetic retinopathy is a silent, but progressive complication of diabetes, and comprises $4.8 \%$ of the global causes of blindness, it is imperative that it is detected early and treated in a timely fashion. Awareness about retinopathy amongst patients with diabetes is an important aspect in the management of diabetes. Aims and Objective: To understand the level of awareness of retinal screening in North Indian patients with diabetes mellitus (DM), attending a tertiary care hospital. Materials and Methods: This was an observational, cross-sectional questionnaire based study, conducted over a 6 month period at a tertiary care hospital in North India. Patients above the age of 18, having an underlying diagnosis of type 1 diabetes mellitus (T1DM) or type 2 diabetes mellitus (T2DM), were included in the study. The Unpaired or independent student t-test were used for the comparison of the mean value of two groups, and the Chi-square test for the comparison of categorical variables. The $p$-value was taken as significant when less than $0.05(p<0.05)$. A Confidence interval of $95 \%$ was used. Results: The mean age of the study subjects was $53.78 \pm 11.24$ years, with a mean age of diagnosis of $46.50 \pm 10.7$ years, and a mean duration of having diabetes of $7.4 \pm 7.61$ years. Glycemic control was sub-optimal, with the mean $\mathrm{HbA} 1 \mathrm{c}$ of the cohort at $9.55 \%$. Of 100 responders, $33 \%$ reported being unaware of the ocular complications of diabetes. Only $48 \%$ stated that their healthcare provider had advised them that they need a routine yearly dilated eye exam. Despite $62 \%$ of the cohort reporting decreased visual acquity, $52 \%$ did not have an eye exam in the preceding year. Conclusion: A large number of our patients remain unaware of the complications of their diabetes, and hence may not be engaged in its management. More longitudinal studies are needed to understand what factors are affecting health literacy in the population. Better sustainable and patient-centric education models need to be developed, that will serve to increase health literacy, and improve patient care.

Key words: Diabetic retinopathy, Awareness, Type 2 diabetes, Glycemic control
Access this article online

Website:

http://nepjol.info/index.php/AJMS

DOI: 10.3126/ajms.v8i6.18058

E-ISSN: 2091-0576

P-ISSN: $2467-9100$

\section{INTRODUCTION}

In the $21^{\text {st }}$ century, diabetes is one of the largest global health emergencies confronting the planet. Four hundred fifteen million individuals are already estimated to have diabetes, with another 318 million noted to have impaired glucose tolerance. Aside from their ramifications on physical and mental health, diabetes and its complications also pose a great burden on the economy. In 2015 alone, the estimated global health spending to treat diabetes and prevent complications was estimated to range from $\$ 673$ billion to $\$ 1,197$ billion. ${ }^{1}$ Bearing this in mind, organizations such as the Research Society for the Study of Diabetes in India (RSSDI) have set forth evidence based treatment guidelines and management algorithms. ${ }^{2}$ However, their translation into clinical practice seems to be lacking. ${ }^{3}$

Since diabetic retinopathy is a silent, but progressive complication of diabetes, and comprises $4.8 \%$ of the global causes of blindness, it is imperative that it is detected early 
and treated in a timely fashion. ${ }^{4}$ The American Diabetes Association (ADA) initially recommends starting with a yearly dilated and comprehensive eye examination. ${ }^{5}$ Given that the reported prevalence in India ranges from 7.3 to $25 \%$, we undertook a study to ascertain the level of awareness of retinal screening in heterogeneous cohort of patients with diabetes mellitus (DM), attending a tertiary care hospital in North India. ${ }^{4}$

\section{MATERIALS AND METHODS}

This was an observational, cross sectional questionnaire based study, conducted at the Max Super Speciality Hospital, Saket, New Delhi, over a period of 6 months (January-June 2014). To meet the inclusion criteria, patients had to be above 18 years of age and have an underlying diagnosis of type 1 diabetes mellitus (T1DM) or type 2 diabetes mellitus (T2DM).All the patients meeting the inclusion criteria, who gave verbal and written consent, were included in the data analysis. Each patient was asked to fill a semi structured questionnaire. The components of the questionnaire included demographic details, diabetes history, pertinent family history, history of other co-morbidities, and a history of complications such as retinopathy. All clinical data was recorded on a Case Report Form. After filling the questionnaire, each patient was given a patient information sheet (PIS) consisting of general information about Diabetic Retinopathy. The study protocol was approved from the Scientific Committee as well as from the Ethics Committee of the Max Super Speciality Hospital, Saket prior to study initiation.

\section{Statistical analysis}

The SPSS (statistical package for social sciences) version 16.0 was used in the statistical analysis of the data set. The values were represented in Number (n), Percentage (\%) and Mean (v). The statistical tests used were the Unpaired or independent student $t$-test for the comparison of the mean value of two groups, and the Chi-square test was used for the comparison of categorical variables. The p-value was taken as significant when less than $0.05(\mathrm{p}<0.05)$. A Confidence interval of $95 \%$ was used.

\section{RESULTS}

A total of 100 individuals diagnosed with T2DM were enrolled in the study, $63 \%$ of which were males. The mean age of the study subjects was $53.78 \pm 11.24$ years. The mean age of diagnosis was $46.50 \pm 10.7$ years, with the mean duration of having diabetes at $7.4 \pm 7.61$ years. Risk factor control was sub-optimal, with the mean $\mathrm{HbA} 1 \mathrm{c}$ of the cohort at $9.55 \%$, mean LDL at $101.46 \mathrm{mg} / \mathrm{dl}$, average fasting blood sugar at $176.28 \mathrm{mg} / \mathrm{dl}$ and average post- prandial blood sugar at $232.05 \mathrm{mg} / \mathrm{dl}$. Off note, $6 \%$ denied that they had been informed of the diagnosis of diabetes.

Out of 100 responders, $67 \%$ reported that they were advised by their treating physician that blindness is a complication of diabetes. 33\% were unaware (Figure 1). Only $26 \%$ of patients expressed awareness that they are at a risk of developing cataracts. Less than half $(48 \%)$ of patients were informed by their healthcare provider that they need a routine yearly dilated eye exam due to their underlying diabetes. The majority (52\% in total) had not had an eye exam in the past year, with $42 \%$ of this cohort indicating that they had not been informed by their doctor to do so. A mere 39\% reported a proper fundoscopic examination being done in which they had their pupils dilated. $62 \%$ of the total study population reported decreased visual acuity, with $5 \%$ of the subjects having documented mild non-proliferative retinopathy. A multivariate analysis (Table 1) did not reveal any statistically significant correlation between factors such as worsening glycemic control or years since the diagnosis of Type 2 diabetes, vis-à-vis a lack of awareness.

\section{DISCUSSION}

One of the greatest threats facing us as a nation, is the growing spread of diabetes and its complications. As per data from the International Diabetes Federation (IDF), India ranks second only to China with 62.9 million individuals already documented to have diabetes. Southeast Asia, as a region, was already documented to have 78.3 million individuals with diabetes, in 2015. ${ }^{1}$ Given this, we need to ensure that the policies and practice measures that we have in place are efficacious in combating this increasing burden of disease. In 2006, the Delhi Diabetes Community (DEDICOM) survey highlighted the practice gap that exists between recommendations and the delivery of diabetes care in Delhi. Out of 819 subjects from over 20,000 households, only 13\% had a HbA1c tested and

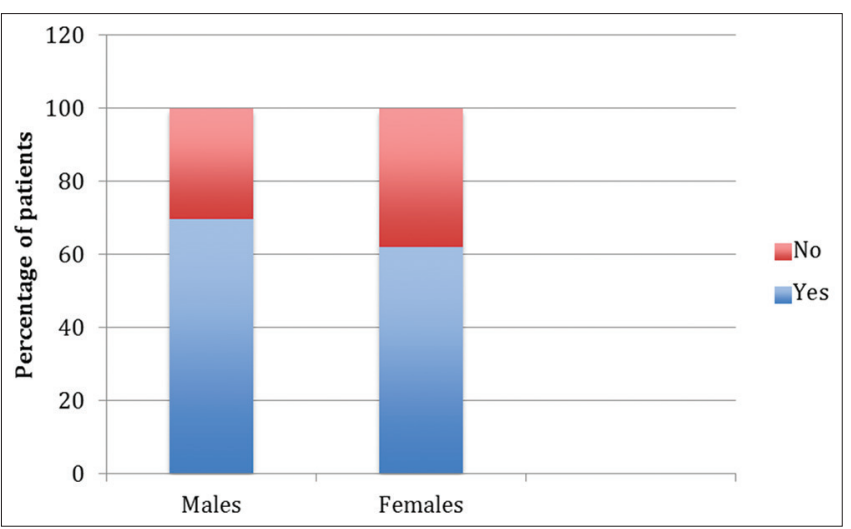

Figure 1: Awareness of Retinopathy amongst the study cohort 


\begin{tabular}{|c|c|c|c|}
\hline Variable & Aware about retinopathy $(n=67)$ & Unaware about retinopathy $(n=33)$ & p-value \\
\hline \multicolumn{4}{|l|}{ Demographic variables } \\
\hline Age (years) & $54.76 \pm 11.14$ & $51.76 \pm 11.33$ & 0.982 \\
\hline Gender-Males & $43 \%$ & $20 \%$ & - \\
\hline Gender-Females & $24 \%$ & $13 \%$ & - \\
\hline Weight $(\mathrm{Kg})$ & $73.54 \pm 69.12$ & $69.12 \pm 10.34$ & 0.169 \\
\hline Height $(\mathrm{cm})$ & $163.4 \pm 10.64$ & $165.52 \pm 9.38$ & 0.986 \\
\hline $\mathrm{BMI}\left(\mathrm{Kg} / \mathrm{m}^{2}\right)$ & $27.52 \pm 5.88$ & $25.03 \pm 3.48$ & 0.324 \\
\hline BP-systolic & $125.28 \pm 12.81$ & $124.79 \pm 15.75$ & 0.226 \\
\hline BP diastolic & $75.25 \pm 7.86$ & $74.39 \pm 7.77$ & 0.873 \\
\hline Age of diagnosis of diabetes (years) & $46.37 \pm 9.95$ & $46.76 \pm 12.28$ & 0.324 \\
\hline \multicolumn{4}{|l|}{ Biochemical parameters } \\
\hline Sodium (mg/dL) & $136.63 \pm 2.55$ & $136.67 \pm 1.50$ & 0.197 \\
\hline Total cholesterol (mg/dL) & $192.3 \pm 46.14$ & $142.25 \pm 38.3$ & 0.982 \\
\hline $\mathrm{LDL}(\mathrm{mg} / \mathrm{dL})$ & $116.86 \pm 47.21$ & $65.67 \pm 25.10$ & 0.602 \\
\hline $\mathrm{HDL}(\mathrm{mg} / \mathrm{dL})$ & $47 \pm 9.57$ & $40 \pm 12.16$ & 0.595 \\
\hline $\mathrm{FBS}(\mathrm{mg} / \mathrm{dL})$ & $179.91 \pm 49.00$ & $169.23 \pm 72.09$ & 0.311 \\
\hline PPBS $(\mathrm{mg} / \mathrm{dL})$ & $238.74 \pm 76.99$ & $223.12 \pm 74.61$ & 0.739 \\
\hline HbA1c (\%) & $9.66 \pm 2.46$ & $9.35 \pm 1.45$ & 0.112 \\
\hline
\end{tabular}

only $16.2 \%$ had a dilated eye exam, a year prior to study enrollment. Interestingly, $61.6 \%$ of the study cohort were aware of the regular need for eye exams. ${ }^{3}$

Our study adds to the literature, as it reaffirms that in a digital age, a practice gap in the delivery of care still exists nearly a decade following the publication of the DEDICOM data. Despite being seen in a tertiary referral center and $62 \%$ of the study cohort reporting decreased visual acuity, only $2 / 3$ of patients stated that they were advised that diabetes can lead to ophthalmic complications like blindness. Less than half reported being advised that they need a regular eye exam, which is in keeping with historical data. Interestingly, no correlation would be seen in terms of a lack of awareness and the duration of diabetes or worsening glycemia, for example.

So, why does this discrepancy exist? Are the guidelines such as those set forth by the ADA or the RSSDI lacking, or are patients not adhering to practice recommendations due to a multitude of underlying barriers to care. It is undisputable that the onus lies on us as a community to translate practice guidelines into prescription plans that are easy to follow and adhere to. However, the need of the hour may be to look the end user (our patients) and see where there is a breakdown in information.

It is well established that healthcare outcomes depend on the adherence of patients to treatment regiments. With some chronic disease states, as many as $40 \%$ of patients may put themselves at risk of complications by ignoring, misunderstanding or forgetting healthcare advice. ${ }^{6}$ For example, an earlier study by Jha et al identified that psychological insulin resistance stemmed from several factors, including a lack of education. This study highlighted the need from better interpersonal interactions between providers and patients, to counter this. ${ }^{7}$ Patient education is key as studies have shown that self-management education can serve to prevent complications such as retinopathy, neuropathy, and nephropathy. ${ }^{8}$ However, this too needs to be tailored according to a patient's socioeconomic circumstances and health literacy. For example, a study by Bhargava et al reported that Hispanic patients with diabetes had less knowledge of their cardiovascular disease risk/protective factors, as opposed to their Caucasian counterparts, due to limited English proficiency. ${ }^{9}$

Our study has several limitations. We do not have data on factors such as language proficiency, background education or socioeconomic strata. We were not able to sample a larger population or sub-divide our study group into the various ethnicities that exist in the populace. However, we feel that the data is representative of the lack of patient education that exists in Indian patients with diabetes mellitus.

\section{CONCLUSION}

The study concludes that a large portion of our patients still remain unaware of the complications of their diabetes, such as retinopathy, and hence may not be as engaged in the care of their chronic disease. This is of grave concern, as in a digital age where information is literally on the fingertips, this should not be the case. More longitudinal studies are needed to understand what factors are affecting health literacy in the population. Better sustainable and patientcentric education models need to be developed, that will 
serve to increase health literacy, and in turn improve patient satisfaction and quality of care.

\section{REFERENCES}

1. International Diabetes Federation. IDF Diabetes Atlas, $7^{\text {th }}$ edn Brussels, Belgium: International Diabetes Federation, 2015. http://www.diabetesatlas.org.

2. RSSDI. RSSDI Clinical Practice Recommendations for Management of Type 2 diabetes Mellitus. RSSDI. 2015.

3. Nagpal J and BhartiaA. Quality of diabetes care in the middle- and high-income group populace: The Delhi Diabetes Community (DEDICOM) survey. Diabetes Care. 2006;29(11):2341-2348.

4. Hussain R, Rajesh B, Giridhar A, Gopalakrishnan M, Sadasivan S, James J, et al. Knowledge and awareness about diabetes mellitus and diabetic retinopathy in suburban population of a South Indian state and its practice among the patients with diabetes mellitus: A population-based study. Indian J Ophthalmol. 2016;64(4):272-276.

5. Cameron F. Standards of Medical Care in Diabetes - 2016. Aust Fam physician. 2006;35(6):386-90.

6. Martin LR, Williams SL, Haskard KB and Dimatteo MR. The challenge of patient adherence. Ther Clin Risk Manag 2005;1(3):189-199.

7. Jha S, Panda M, Kumar S, Gupta R, Neemani A, Jacob J, et al. Psychological Insulin Resistance in Patients with Type 2 Diabetes. J Assoc Physicians India 2015;63(7):33-39.

8. Schäfer I, Pawels M, Küver $C$, Pohontsch $N J$, Scherer M, van den Bussche $\mathrm{H}$, et al. Strategies for Improving Participation in Diabetes Education. A Qualitative Study. Ribera JM, editor. PLoS One. 2014;9(4):e95035.

9. Bhargava A, Wartak SA, Friderici $J$ and Rothberg MB. The Impact of Hispanic Ethnicity on Knowledge and Behavior Among Patients With Diabetes. Diabetes Educ 2014; 40(3):336-343.

\section{Authors Contribution:}

MA- Data collection, literature review; SS- Statistical analysis \& interpretation of results, manuscript revisions; SW-Reviewed the manuscript; AB-Manuscript preparation and critical revisions; $\mathbf{S} \mathbf{J}$ - Concept and design of the study, reviewed the manuscript.

Orcid ID:

Munazir Adil: (1) http://orcid.org/0000-0002-8481-3943

Samreen Siddiqui: (D) http://orcid.org/0000-0001-6234-2856

Dr. Swati Waghdhare: (1) http://orcid.org/0000-0001-9535-1070

Dr. Amit Bhargava: (1) http://orcid.org/0000-0001-9671-0776

Dr. Sujeet Jha: (1) http://orcid.org/0000-0002-1283-4606

Source of Support: Nil, Conflict of Interest: None declared. 